\title{
Chemopreventive potential of alpha lipoic acid in the treatment of colon and cervix cancer cell lines
}

\author{
Damnjanovic $\mathrm{I}^{1}$, Kocic $\mathrm{G}^{2}$, Najman $\mathrm{S}^{3}$, Stojanovic $\mathrm{S}^{3}$, Stojanovic $\mathrm{D}^{4}$, Veljkovic $\mathrm{A}^{2}$, \\ Conic $\mathrm{I}^{5}$, Langerholc $\mathrm{T}^{6}$, Pesic $\mathrm{S}^{7}$
}

Department of Pharmacy, Faculty of Medicine, University of Nis, Serbia. ivanad.ph@gmail.com

\begin{abstract}
Objectives: The nuclear factor $\mathrm{KB}$ regulates the expression of genes involved in many processes that play a key role in the development and progression of cancer. The aim of this study was to examine the influence of the alpha lipoic acid in the chemoprevention of colon and cervix carcinoma in vitro.

Background: In recent years, special attention has been paid to the potential chemopreventive properties of antioxidants. There are no published data on the impact of alpha lipoc acid of chemoprevention of cervix and colon cancer. Methods: We examined the effect of alpha lipoic acid alone or in combination with cisplatin and 5-fluorouracil on proliferation of the two cell lines, HeLa (human cervical carcinoma cells) and Caco-2 (human colon cancer cells) by MTT test. The measurement of the level of transcription factor NF-KB was also performed in the cells of both cell lines. Results: At least one of the mechanisms of the antiproliferative and/or cytotoxic effect of alpha lipoic acid on Caco-2 and HeLa cells at high concentrations, the transcription factor NF-KB, may be involved, as well as the products of transcription of genes that are under its control.

Conclusion: The alpha lipoic acid has proven to be a promising candidate in the combat arena against cancer (Tab. 4, Ref. 31). Text in PDF www.elis.sk.

Key words: alpha lipoic acid, chemoprevention, HeLa cells, Caco-2 cells, nuclear factor KB.
\end{abstract}

Colon cancer is a highly frequent form of malignancy (1). It is considered the third most common malignancy diagnosed in the population of Europe and as such is a major health and socioeconomic problem (2). Cervix cancer with its incidence being slightly more common than colon carcinoma, takes the second place and has recorded an increase in the number of patients in developing countries (3). Chemoprevention may be one of the most important components of cancer prevention and is based on the use of chemical agents from the nature that surrounds us, as well as synthetic analogues, which may block tumor initiation and promotion of events, which mark stages in the development of tumors (4). A new approach to cancer chemoprevention is based on coadministration of two or more substances, of different mode of effect, the aim of which is to intensify the activity, which would bring down side-effects to a minimum (5).

${ }^{1}$ Department of Pharmacy, Faculty of Medicine, University of Nis, Serbia, ${ }^{2}$ Institute of Biochemistry, Faculty of Medicine, University of Nis, Serbia, ${ }^{3}$ Institute of Biology and Human Genetics, Faculty of Medicine, University of Nis, Serbia, ${ }^{4}$ Institute of Pathophysiology, Faculty of Medicine, University of Nis, Serbia, ${ }^{5}$ Clinic of Oncology Clinical Center of Nis, Serbia, ${ }^{6}$ Faculty of Medicine, University of Maribor, Slovenia, and ${ }^{7}$ Department of Pharmacology, Faculty of Medicine, University of Nis, Serbia

Address for correspondence: I. Damnjanovic, PharmD, Department of Pharmacy, Faculty of Medicine, Bulevar dr Zorana Dindica 81, 18000 Nis, Serbia.

Phone: +381.600798309 , Fax: +381.184238770

Acknowledgements: The study was supported by the Ministry of Science and Technological Development of the Republic of Serbia (project No. TR 31060 and project No. 41017).
In recent years, special attention has been paid to the potential chemopreventive properties of antioxidants. Alpha lipoic acid (ALA) is one of the most efficient known endogenous antioxidants, and in recent years has taken a special place as an anticancer agent (6). ALA shows an antiproliferative effect and inhibits the growth of colon cancer cells in vitro $(7,8)$. The activation of transcription factor nuclear factor-kappa $\mathrm{B}(\mathrm{NF}-\mathrm{\kappa B})$ regulates various genes involved in the proliferation, invasion, angiogenesis, and metastasis of cancer cells. NF- $\kappa \mathrm{B}$ is important to study in solid tumors because of its potential to act downstream of a number of oncogenic pathways making it a desirable therapeutic target with potential for activity across a broad range of cancers (9). There are no published data on the impact of ALA on cervix carcinoma cells, nor data about the impact of chemoprevention of colon and cervix cancer. Therefore, the aim of this study was to examine the influence of the alpha lipoic acid in the chemoprevention of colon and cervix carcinoma in vitro.

\section{Materials and methods}

\section{Chemicals}

following substances were purchased for experiments: alpha lipoic acid, cisplatin and 5-fluorouracil as follows: alpha lipoic acid (Berlition ED 300, Berlin-Chemie, Germany, $300 \mathrm{mg} / 12 \mathrm{ml}$ ), cisplatin (Cisplatin Ebewe, Ebewe Pharma Austria, $10 \mathrm{mg} / 20 \mathrm{ml}$ ) and 5-fluorouracil (Fluorouracil Teva, Pharmachemie BV - Netherlands, $50 \mathrm{mg} / \mathrm{ml}$ ). DMEM (Dulbecco's Modified Eagle Medium), FBS (Fetal Bovine Serum), Antibiotic-Antimycotic solution, 
611-616

L-Glutamine and Trypsin-EDTA solution were purchased from PAA Laboratories, Austria and 3-(4,5-dimethylthiazol-2-yl)-2,5diphenyltetrazolium bromide (MTT) was purchased from Carl Roth, Germany. Trypan Blue Stain was purchased from Invitrogen. Primary anti- NF- $\kappa \mathrm{B}$ antibody and secondary antibody were purchased from Santa Cruz Biotechnology (C-20:sc-372 epitope mapping at C-terminalals of NF- $\kappa \mathrm{B}$, Santa Cruz, CA, USA). Cytostatics - 5-fluorouracil and cisplatin, according to the protocol, are used in the treatment of colon and cervix carcinoma $(10,11)$.

\section{Concentration for in vitro study}

Alpha lipoic acid (ALA), cisplatin (CP) and 5-fluorouracil (5-FU) were diluted in DMEM and three concentrations of each of these substances were tested (group 1 - the lowest concentration, group 2 - middle concentration and group 3 - the highest concentration). Final concentrations of the tested substances were the following: 10,100 and $1000 \mu \mathrm{M}$ of alpha lipoic acid, 1.66, 3.32 and $6.64 \mu \mathrm{M}$ of cisplatin and 10,100 and $1000 \mu \mathrm{M}$ of 5-fluorouracil. We have also combined alpha lipoic acid with cisplatin and 5-fluorouracil, respectively. Combining was performed using substance concentrations from the same group as the following: group 1 with group 1, group 2 with group 2 and group 3 with group 3 in the ratio $1: 1$ so that the effective concentrations of substances in combinations were twice less than the concentrations of substances that were applied alone

\section{Cell lines}

For this experiment, we used two cell lines, HeLa S3 (human cervical carcinoma cells) which were obtained from the Leibniz Institute DSMZ and Caco-2 (human colon cancer cells) which were obtained from ATCC. Cells were cultured in DMEM supplemented with $10 \% \mathrm{FBS}, 2 \mathrm{mM}$ L-glutamine, and antibiotic/antimycotic solution at $37{ }^{\circ} \mathrm{C}$ in an atmosphere with $5 \% \mathrm{CO}_{2}$ and saturated humidity. Replacement of the culture medium was performed every 2 to 3 days.

\section{Cell proliferation assay}

When cells of both cell lines reached approximately $80 \%$ confluence, the cells were harvested using Trypsin/EDTA solution, washed in buffer solution and the total number of cells was determined by Trypan blue dye exclusion test. Cells were planted in 96 well plates at density $2 \times 10^{4}$ cells per well and cultured for 24 hours under standard cell culture conditions. After that the examined substances, alone or combined, were added to the cells in the tested concentrations. As a control, we used cells that were incubated only with completed cell culture medium supplement with FCS without additional substances. The effect of tested substances on cell proliferation was determined after 48 hours of incubation by performing MTT test.

\section{MTT test}

MTT test is based on the reduction of MTT to purple formazan crystals that are insoluble in water. The medium, in which the cells were incubated with or without additional substances, was discarded at the end of the incubation period. Cells were washed with buffer solution and $20 \mu \mathrm{L}$ of MTT solution was added to each well at concentration of $1 \mathrm{mg} / \mathrm{ml}$. Three hours after incubation of cells with MTT at $37{ }^{\circ} \mathrm{C}$, the resulting formazan crystals were dissolved with $100 \mu \mathrm{L}$ of 2-propanol. Spectrophotometric measurement of MTT reduction, or intensity of the purple color, was performed at a wavelength of $540 \mathrm{~nm}$ on an ELISA plate reader (Multiscan Ascent, Thermo Labsystems). The intensity of purple color was in direct correlation with the number of viable cells. Results are presented as the average value of absorbance \pm standard deviation from four to eight replications for all tested substances as well as control.

\section{Measurement of the level of transcription factor $N F-\kappa B$}

The cells of both cell lines were seeded into 96 well plates with the density of $3 \times 10^{4}$ cells/well, respectively, and cultivated in the standard cell culture conditions for 24 hours. After that period, the substances were added in concentrations and combinations, examined, and the cells were incubated for the next 48 hours. Further protocol was performed according to the Kocic (12). Briefly, the cells were washed in PBS and fixed by using $70 \%$ methanol and permeabilized with $0.1 \%$ Triton PBS. The cells were incubated with the primary anti-NF- $\mathrm{BB}$ antibody, washed three times, and incubated with the FITC-conjugated secondary antibody. The mean fluorescence intensity (MFI; logarithmic scale) of the cells was determined and analyzed on a Victor TM multiplate reader (Perkin Elmer-Wallace, Wellesley, MA). The results presented were obtained following the subtraction of blank values treated with the secondary antibodies only.

\section{Statistical analysis}

The data were analyzed by the means of commercially available statistics software package (SPSS for Windows ${ }^{\circledR}$, v. 17.0, Chicago, USA) using the Students' t-test and the ANOVA test. The results were presented via $\pm / \mathrm{SD}$. The statistical significance was set to $\mathrm{p}<0.05$.

\section{Results}

The results of the MTT test after incubating the Caco- 2 cells with the substances are shown in Table 1.

The T-test of the independent samples was compared to the testing results of the alpha lipoic acid at three different concentrations on the proliferation in the culture Caco- 2 cells compared to the control group (cells in medium without additional active substances). There was a significant reduction in the proliferation in dose-dependent manner (pALA3 $<0.001$ and pALA2 $<0.001$ ). The ANOVA showed a statistical significance between groups ALA1, ALA2 and ALA3 ( $\mathrm{p}<0.001$ ). Subsequent comparisons using the Tukeyev HSD test indicated that the mean values of all the groups were statistically significantly different (pALA32 = 0.004 , pALA $31<0.001$ and pALA2 $1<0.001$ ).

In the groups treated with cisplatin, there was a statistical significance compared to the control group only for Group 3 ( $p<$ $0.001, \mathrm{pCP} 3<0.001)$ and Group $1(\mathrm{p}<0.05, \mathrm{pCP} 1=0.010)$. The ANOVA examined the statistical significance between the groups 
Tab. 1. The results of the MTT test after incubating the Caco-2 cells with the substances.

\begin{tabular}{|c|c|c|c|c|}
\hline & Group 1 & Group 2 & Group 3 & Control \\
\hline & $\mathrm{x} \pm \mathrm{SD}$ & $\mathrm{x} \pm \mathrm{SD}$ & $\mathrm{x} \pm \mathrm{SD}$ & $\mathrm{x} \pm \mathrm{SD}$ \\
\hline ALA & $0.923 \pm 0.048$ & $0.806 \pm 0.029^{* * *}$ & $0.131 \pm 0.008^{* * *}$ & . \\
\hline $\mathrm{CP}$ & $0.878 \pm 0.053^{*}$ & $0.810 \pm 0.118$ & $0.375 \pm 0.010^{* * * *}$ & ஜ \\
\hline $\mathrm{FU}$ & $1.039 \pm 0.175$ & $0.998 \pm 0.043$ & $0.887 \pm 0.028^{* *}$ & $\begin{array}{c}\infty \\
0 \\
0\end{array}$ \\
\hline ALA-CP & $0.871 \pm 0.138$ & $0.889 \pm 0.012^{*}$ & $0.233 \pm 0.015^{* * *}$ & 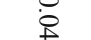 \\
\hline ALA-FU & $0.957 \pm 0.048$ & $0.878 \pm 0.030^{* *}$ & $0.282 \pm 0.069^{* * *}$ & \\
\hline
\end{tabular}

"p $<0.05, " \mathrm{p}<0.01, " \mathrm{*} \mathrm{p}<0.001$

$\mathrm{CP} 1, \mathrm{CP} 2$ and $\mathrm{CP} 3$ (pCP $<0.001)$. Subsequent comparisons using the Tukeyev HSD test showed that the mean value of the CP3 group was different from the $\mathrm{CP} 1$ and $\mathrm{CP} 2$ groups $(\mathrm{pCP} 32<$ 0.001 and $\mathrm{pCP} 31<0.001)$. In groups treated with 5 -fluorouracil, there was a statistical significance compared to the control group in Group $3(\mathrm{p}<0.01, \mathrm{pFU} 3=0.007)$. The combination of alpha lipoic acid /cisplatin, as compared to the control group, showed a statistically significant inhibition proliferation in the Group 3 $(\mathrm{p}<0.001$, pALA-CP3 $<0.001)$ and Group 2 ( $<<0.05$, pALA$\mathrm{CP} 2=0.013)$. The ANOVA examined the statistical significance between the groups ALA-CP1, ALA-CP2 and ALA-CP3. There was a statistically significant difference at the level of pALA-CP $<0.001$. Subsequent comparisons using the Tukeyev HSD test, showed that the mean value in the ALA-CP3 group differed from those in groups ALA-CP2 and ALA-CP1 (pALA-CP32 $<0.001$ and pALA-CP31 < 0.001).

The combination of alpha lipoic acid/fluorouracil in the highest dose, compared to the control group, showed to be statistically significant $(\mathrm{p}<0.001, \mathrm{pALA}-\mathrm{FU} 3<0.001)$ and in the Group 2 $(\mathrm{p}<0.01, \mathrm{pALA}-\mathrm{FU} 2=0.009)$. The ANOVA showed a statistical significance between the groups ALA-FU1, ALA-FU2 and ALAFU3. There was a statistically significant difference at the level of pALA-FU $<0.001$. Subsequent comparisons using the Tukeyev HSD test showed that the mean value in the LC3 group differed from those in the groups ALA-FU1 and ALA-FU2 (pALA-FU3-2 $<0.001$ and pALA-FU3- $1<0.001$.)

The results of the MTT test after incubating the HeLa cells with the tested substances are shown in Table 2.

The T-testing of the independent samples was compared to the results of the alpha lipoic acid at three different concentrations on the cultured cell proliferation compared to the control group. A significant reduction in cell proliferation was in dose dependent manner $(\mathrm{p}<0.001$, pALA3 $<0.001, \mathrm{p}<0.01$, pALA2 $=0.004$ and pALA1 $=0.001)$. The ANOVA showed a statistical significance between the groups ALA1, ALA2 and ALA3. There was a

Tab. 2. The results of the MTT test after incubating the HeLa cells with the tested substances.

\begin{tabular}{|c|c|c|c|c|}
\hline & Group 1 & Group 2 & Group 3 & Control \\
\hline & $\mathrm{x} \pm \mathrm{SD}$ & $\mathrm{x} \pm \mathrm{SD}$ & $\mathrm{x} \pm \mathrm{SD}$ & $\mathrm{x} \pm \mathrm{SD}$ \\
\hline ALA & $1.326 \pm 0.010^{* *}$ & $1.374 \pm 0.022^{* *}$ & $0.833 \pm 0.025^{* * *}$ & $\vdash$ \\
\hline $\mathrm{CP}$ & $1.051 \pm 0.008^{* * *}$ & $0.853 \pm 0.050^{* * * *}$ & $0.681 \pm 0.050^{* * *}$ & نn \\
\hline FU & $1.360 \pm 0.042^{* *}$ & $1.300 \pm 0.040^{* * * *}$ & $1.325 \pm 0.016^{* *}$ & 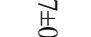 \\
\hline ALA-CP & $1.276 \pm 0.034^{* * *}$ & $1.248 \pm 0.117^{* *}$ & $0.984 \pm 0.027^{* * *}$ & : \\
\hline ALA-FU & $1.350 \pm 0.054^{* *}$ & $1.378 \pm 0.010^{* * *}$ & $1.284 \pm 0.029^{* * *}$ & $\infty$ \\
\hline
\end{tabular}

Tab. 3. The level of transcriptional factor NF-кB in the culture of Caco-2 cells.

\begin{tabular}{|c|c|c|c|c|}
\hline & Group 1 & Group 2 & Group 3 & Control \\
\hline & $\mathrm{x} \pm \mathrm{SD}$ & $\mathrm{x} \pm \mathrm{SD}$ & $\mathrm{x} \pm \mathrm{SD}$ & $\mathrm{x} \pm \mathrm{SD}$ \\
\hline ALA & $3995.50 \pm 172.99^{*}$ & $4411.25 \pm 965.02$ & $3271.25 \pm 1358.29^{*}$ & 胫 \\
\hline $\mathrm{CP}$ & $4799.75 \pm 1131.39$ & $4060.25 \pm 921.07^{*}$ & $2991.75 \pm 707.12^{* *}$ & $\stackrel{n}{ \pm}$ \\
\hline FU & $5023.00 \pm 1629.41$ & $3832.50 \pm 1037.89^{*}$ & $4329.75 \pm 831.54$ & 7 \\
\hline ALA-CP & $5632.00 \pm 741.26$ & $4186.33 \pm 1087.19$ & $2248.33 \pm 710.23^{* *}$ & $\overrightarrow{\breve{d}}$ \\
\hline ALA-FU & $5420.33 \pm 1155.81$ & $4662.67 \pm 817.96$ & $870.00 \pm 996.01^{* * * *}$ & a \\
\hline
\end{tabular}

statistically significant difference $(p<0.001)$. Subsequent comparisons using the Tukeyev HSD test showed that the mean value of Group 3 was significantly different than those in the Groups 2 and 1 (pALA32 < 0.001 and pALA31<0.001).

All three groups treated with cisplatin showed a statistically significant decrease in cell proliferation compared to the control group ( $\mathrm{p}<0.001, \mathrm{pCP} 3<0.001, \mathrm{pCP} 2<0.001$ and $\mathrm{pCP} 1<$ $0.001)$. Also, there was a statistically significant difference $(\mathrm{p}<$ 0.001 ) estimated by the ANOVA between groups CP1, CP2 and CP3 ( $\mathrm{pCP}<0.001)$. Subsequent comparisons using the Tukeyev HSD test indicated that the mean values of the three groups differed significantly $(\mathrm{pCP} 32=0.005, \mathrm{pCP} 31<0.001$ and $\mathrm{pCP} 21=$ $0.003)$. The combination of alpha lipoic acid / cisplatin as compared to the control group, showed a statistical significance in the Groups 3 and $1(\mathrm{p}<0.001$, pALA-CP $3<0.001$ and pALA-CP $1<$ $0.001)$ and Group $2(\mathrm{p}<0.01, \mathrm{pALA}-\mathrm{CP} 2=0.001)$. The ANOVA recorded a statistical significance between the groups ALA-CP1, ALA-CP2 and ALA-CP3. There was a statistically significant difference $(\mathrm{p}<0.01$, $\mathrm{pALA}-\mathrm{CP}=0.005)$. Subsequent comparisons using the Tukeyev HSD test showed that the mean value of Group 3 significantly differed from those of Groups 2 and 1, pALA-CP32 $=0.010$ and pALA-CP3 $1=0.006$.

In the groups treated with 5-fluorouracil, a statistical significance was found between the control group and Group $2(\mathrm{p}<0.001$, pFU2 $<0.001$ ), whereas in the Group 3 and 1 , the statistical significance was set at $\mathrm{p}<0.01,(\mathrm{pFU} 3=0.001$ and $\mathrm{pFU} 1=0.003)$. The combination of alpha lipoic acid/5-fluorouracil in comparison to the control group showed a statistical significance in all three groups, $(\mathrm{p}<0.001)$ in the Group 3, pALA-FU3 $<0.001$, and in the Groups $2(\mathrm{p}<0.01)$ and 1 , pALA-FU2 $=0.005$, pALA-FU1 $=$ 0.003 . The ANOVA showed statistically significant differences ( $\mathrm{p}$ $<0.05, \mathrm{pLC}=0.045$ ). Subsequent comparisons using the Tukeyev HSD test showed that the mean value of Group 3 significantly differed from Group 2 (pALA-FU32 = 0.42).

The levels of transcriptional factor NF- $\mathrm{KB}$ in the Caco- 2 cells culture are shown in Table 3.

The T-testing of independent samples was compared to the results of the alpha lipoic acid at three different concentrations on the levels of transcriptional factor NF- $\mathrm{BB}$ in the Caco- 2 cells culture compared to the control group. There was a significant reduction in the levels of NF- $\mathrm{\kappa B}$ in culture in the Groups 3 and $1(\mathrm{p}<0.05$, $\mathrm{pALa} 3=0.025$, pALA1 $=0.025$ ). The ANOVA tested a statistical significance between the groups L1, L2 and L3.

In the groups treated with cisplatin, there was a statistically significant difference in the Group $3(\mathrm{p}<0.001)$ and the Group 2 
611-616

Tab. 4. The level of transcriptional factor NF-kB in the culture of the HeLa cells.

\begin{tabular}{|c|c|c|c|c|}
\hline & Group 1 & Group 2 & Group 3 & Control \\
\hline & $\mathrm{x} \pm \mathrm{SD}$ & $\mathrm{x} \pm \mathrm{SD}$ & $\mathrm{x} \pm \mathrm{SD}$ & $\mathrm{x} \pm \mathrm{SD}$ \\
\hline ALA & $11125.3 \pm 1144.1$ & $10669.8 \pm 897.6$ & $4223.5 \pm 753.2^{* * *}$ & $\overline{8}$ \\
\hline $\mathrm{CP}$ & $7197.5 \pm 338.5^{* *}$ & $6556.0 \pm 918.2^{* *}$ & $4307.2 \pm 1979.2^{* * *}$ & $\stackrel{t}{a}$ \\
\hline FU & $12086.3 \pm 1238.8$ & $9993.0 \pm 4097.6$ & $13553.3 \pm 176.1^{\dagger \dagger}$ & $\dot{\infty}$ \\
\hline ALA-CP & $11049.5 \pm 1519.8$ & $10163.7 \pm 1326.6$ & $7681.0 \pm 2742.0$ & ลิ \\
\hline ALA-FU & $11215.3 \pm 720.7$ & $11632.7 \pm 825.8$ & $10974.7 \pm 3385.0$ & $\ddot{i n}$ \\
\hline
\end{tabular}

$(\mathrm{p}<0.05)$ compared to the control group $(\mathrm{pCP} 3=0.002$ and $\mathrm{pCP} 2$ $=0.040)$. In the groups treated with 5 -fluorouracil, a statistical significance was found only between the control group and the Group $2(\mathrm{p}<0.05, \mathrm{pFU} 2=0.024)$. The combination of alpha lipoic acid / cisplatin, as compared to the control group, showed a statistical significance only in theGroup $3(\mathrm{p}<0.01$, pALA-CP3 $=0.001)$. The ANOVA examined the statistical significance between the groups ALA-CP1, ALA-CP2 and ALA-CP3 ( $<<0.01$ pALA-CP $=0.009$ ). Subsequent comparisons using the Tukeyev HSD test showed that the mean value in the ALA-CP3 group differed from that in the group ALA-CP1 (pALA-CP31 $=0.007$ ).

Combined, alpha lipoic acid/5-fluorouracil were compared to the control group and the test showed a statistical significance only in the Group 3 ( $\mathrm{p}<0.001$, pALA-FU3 $<0.001)$. The ANOVA examined the statistical significance between the groups ALA-FU1, ALA-FU2 and ALA-FU3 $(p<0.01$ pALA-FU $=0.003)$. Subsequent comparisons using the Tukeyev HSD test showed that the mean value of group ALA-FU3 was different from those in the groups ALAFU2 (p ALA-FU32 =0.008) and ALA-FU1 (pALA-FU31 =0.003).

The levels of transcriptional factor NF- $\kappa$ B in the HeLa cells culture are shown in Table 4.

The T-testing of the independent samples was used to compare the results of the alpha lipoic acid at three different concentrations on the levels of transcriptional factor NF- $\mathrm{kB}$ of the cells in culture compared to the control group. There was a significant reduction in cell proliferation in the culture in the group 3, pALA3 $<0.001$. The ANOVA examined the statistical significance between the groups ALA1, ALA2 and ALA3 $(p<0.001)$. Subsequent comparisons using the Tukeyev HSD test showed that the mean value of the group ALA3 differs from those in the groups ALA2 and ALA1 (pALA32 $<0.001$ and pALA31<0.001).

In the groups treated with cisplatin there were statistically significant differences between all groups compared to the control group, in the Group 3 at $\mathrm{p}<0.001, \mathrm{pCP} 3<0.001$ and in the other two groups at $\mathrm{p}<0.01,=\mathrm{pCP} 20.002$ and $\mathrm{pCP} 1=0.004$. The ANOVA examined the statistical significance between the groups $\mathrm{CP} 1, \mathrm{CP} 2$ and $\mathrm{CP} 3$. There was a statistically significant difference $(\mathrm{p}<0.05, \mathrm{pCP}=0.025)$. Subsequent comparisons using the Tukeyev HSD test showed that the mean value of group ALA-CP3 differed from that in the Group ALA-CP1 (pALA-CP31 $=0.026)$. However, the Group 3 even showed a statistically significant increase $(\mathrm{p}<0.05, \mathrm{pFU} 3=0.012)$. The combination of alpha lipoic acid both with cisplatin and 5-fluorouracil, showed no statistical significance as compared to both the control group and between the groups themselves.

\section{Discussion}

Literature data indicates that the ALA acts as an anti apoptotic agent in a variety of cell cultures, preventing oxidant-induced cell death, and induces apoptosis in cancer cells (13). The ALA has an anticancerogenic potential due to the self-elimination free radicals, including the hydroxyl radical, which is included in all stages of cancer, and which is considered to be responsible for the increase in the number of metastases. Its highly antiproliferative effect, ALA has shown on the cancer cell lines in the culture (14). ALA was documented to increase the effectiveness of other antioxidants (vitamin C and E, coenzyme Q10 and glutathione) and significantly increases glutathione levels for 30-70\%, especially in the cells of the liver, lung and kidney of laboratory animals when injected as an antioxidant. The effect of this antioxidant on the glutathione level is important because glutathion significantly affects the synthesis of the harmful cytokines and adhesion molecules that affect NF- $\kappa \mathrm{B}$ activity (15).

In our research, the results of MTT test showed that lipoic acid has strong cytotoxic and/or antiproliferative effects on the Caco2 cells, especially marked at the highest concentration examined. Combined with standard anticancer drugs, lipoic acid enhances its cytostatic effect, especially marked at the highest concentrations tested making and this effect was even more emphasised when combined with 5-FU.

The MTT test of cell proliferation in culture of the Caco-2 cell line showed the expected effect on the proliferation of cells in the group treated with 5-FU. 5-FU expressed cytostatic effect applied in the highest tested concentration only in the Caco cell line. The effect of the 5-FU on cell proliferation may be considered expected if we take into account the potential of the colon cancer cells to develop the resistance to the action of 5-FU. There are several pathways that may be responsible for the development of the resistance to the action of 5-FU (16). The thymidylate synthase (TS) participates in methylation reactions with deoksiuridin monophosphate (dump) using the 5.10-methylene tetrahidrofolata for synthesize deoxitimidine monophosphate (dTMP). Because of this essential role in the thymidylate synthase, it may be a target for the action location of chemoprevention agents such as 5-FU and 5-fluorouracil deoxiribosis. Both drugs are converted to 5-monophosphate fluorodeoxiuridine (5FdUMP), a nucleotide with a cytotoxic effect achieved by forming a stable complex with thymidylate synthase and folate cofactor (5.10 methylentetrahydropholate). The mechanisms of resistance include increased intracellular levels of thymidylate synthase, the development of mutant forms of the enzyme, and a low affinity for 5-FdUMP folate cofactors that may later result in reduced activity of thymidylate synthase $(17,18)$. Another way of resistance can be explained by a decreased transport of nucleosides and nucleobases in cells by nucleoside / nucleobase transporters (19), while some authors have found that the p53 status and DNA defects recovery may be important resistance causes (20).

The HeLa cell line showed a different pattern of response to the applied treatments. MTT test has shown weaker cytotoxic and/ or antiproliferative effect of lipoic acid on HeLa cells compared to 
Caco-2 cells. Besides, alpha lipoic acid exested a protective effect on HeLa cells when combined with cytostatics, which was quite the opposite to its effect on the Caco-2 cells.

The highest concentration of ALA and the combination of 5-FU acted as strong cytostatics in the Caco2 cells, while showing no cytostatic effect on the HeLa cells. Lower concentrations of these drugs combinations do not act as cytostatics in the HeLa cells nor the Caco cells. Cisplatin showed a stronger effect on the HeLa cell line than on the Caco cell lines. The strongest effect was achieved by using the highest concentration of CP3 when the concentration expressed a moderate cytostatic effect in both cell lines. The values, compared to the control, were similar for both cell lines when the highest concentration were used while the difference in effect may be seen at lower concentrations. The highest concentration combination acts as an extreme cytostatic in the Caco-2 cells and as a mild cytostatic in the HeLa cells. Low concentrations of this drug combination showed lower effect on the HeLa cells compared to Caco-2 cells (Tabs 1,2).

The NF- $\kappa \mathrm{B}$ is an inducible transcription factor that mediates the signal transduction between the nucleus and the cytoplasm in a number of cell types and controls the expression of many genes involved in cell growth, differentiation, apoptosis regulation, cytokine production, and neoplastic transformation (21). In mammals, the NF- $\kappa B$ is made up of five different elements: RelA (p65), RelB,

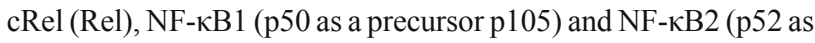
a precursor $\mathrm{p} 100)$. During the stimulation by tumor necrosis factor alpha (TNF- $\alpha$ ) or IL-1, viruses and free radicals affect the phosphorylation of the inhibitory molecules ( $\mathrm{I} \kappa \mathrm{B})$, when it degrades and it becomes an active form of NF- $\kappa \mathrm{B}(22)$. Constitutively increased concentration and induction of NF- $\kappa \mathrm{B}$ has been demonstrated in many cancers, including colorectal cancer (23). The induction of $\mathrm{NF}-\kappa \mathrm{B}$ leads to the development of the resistance to chemotherapy. On the other hand, it has been found that NF- $\mathrm{\kappa B}$ may be a predictor of cellular response to a given chemotherapeutic agent (24). The data are controversial, because in some therapy procedures, $\mathrm{NF}-\kappa \mathrm{B}$ positive tumors are more responsive to therapy in a state of advanced colorectal cancer (when applying cetuximab), while other data indicate that NF- $\mathrm{BB}$ negative tumors exhibit greater sensitivity to therapy. As a typical inducible transcription factor, $\mathrm{NF}-\mathrm{\kappa B}$ is activated in conditions of an increased oxidative stress and as such, it is the strongest inducer of the primary inflammatory response. It has been shown that there is a constitutive induction of NF- $\mathrm{\kappa B}$ in the states of increased presence of mucosa and microflora during of chronic inflammation. Chronic inflammation is a fertile ground for carcinogenesis, suggesting that epigenetic factors can induce differentiation of the cancerous colon, and the presence of elevated concentrations of NF- $\kappa \mathrm{B}$ in the tumor tissue favors metastasis. The most likely reason that a combination of cytostatic and alpha lipoic acid exerts an inhibitory effect on the NF- $\kappa \mathrm{B}$ levels would be strong antioxidant properties of the alpha lipoic acid, which thereby reduce the inducible effect. But the fact that the ALA applied solely and thus was not being able to completely suppress the synthesis and the activation of the NF- $\kappa B$, acknowledges that cancer cells produce a constitutive NF- $\kappa B$ not only in response to the epigenetic factors (oxidative stress), but most likely as a mode for their survival $(25,26,27)$. This is why it is inexplicable that the combined use of lipoic acid and 5-FU has resulted in increased effect of the cytostatic applied. Uezsuka et al. showed that the reduction of NF- $\mathrm{KB}$ activity induces apoptosis and reduces resistance to 5-FU, suggesting that an increased regulation of the inducible factors may be directly and indirectly associated with cell proliferation and the inhibition of apoptosis (28).

Similar results exist concerning the HeLa cells. It has been found that the activated NF- $\mathrm{kB}$ has a positive effect on cell growth, while inhibiting the activity by forming stable complexes with the inhibitors reduced and slowed the movement of tumor cells in the G2 phase from the cell cycle S period (29). The results obtained in our study showed that the alpha lipoic acid was also the case when there is resistance to chemotherapy, as is the case for the action of 5-FU on test cells. This only confirmed the fact that in the case of this type of cancer, there is a constitutive activation of NF and epigenetic $-\kappa \mathrm{B}$, which is even more intense while applying small doses of the alpha lipoic acid or cytostatics. Obtained results together with our data may suggest that it is the most important to apply the adequate dose of the drug.

On several in vitro models have shown that inhibition and reduced activity of NF- $\mathrm{BB}$ is associated with decreasing of MTT reduction, which shows that there is cytotoxic, apotototic and/or antiproliferative effect $(30,31)$. Our treatments have generally shown that decrease of NF- $\kappa$ B activity went along with the decline of MTT test values. Since the inhibition of growth of cancerous cells HeLa and Caco- 2 was associated with the inhibition of NF- $\mathrm{KB}$, this powerful transcription factor in the regulation of cell fate can be one of the ways through which the antiproliferative effect of ALA performed.

\section{Conclusion}

The data showed that chemotherapy in treating colon and cervix cancer should be conducted in accordance with the possible epigenetic effects and constitutive state of the cellular determinants of survival. The combination of the alpha lipoic acid with conventional cytostatic treatment achieved the best effects at highest doses. According to our results, ALA has proven to be a promising candidate in the combat arena against cancer.

\section{References}

1. Vivek V, Sankar NS. Chemopreventive effects of NSAIDs on cytokines and transcription factors during the early stages of colorectal cancer. Pharmacol Rep 2011; 63 (5): 1210-1221.

2. Zavoral M, Suchanek S, Zavada F, Dusek L, Muzik J, Seifert B, Fric P. Colorectal cancer screening in Europe. World J Gastroenterol 2009; 15 (47): 5907-5915.

3. Oaknin A, Diaz De Corcuera I, Rodriguez- Freixinos V, Rivera F, Del Campo JM. SEOM guidelines for cervical cancer. Clin Transl Oncol 2012; 14 (7): 516-519.

4. Langman MJ, Cheng KK, Gilman EA, Lancashire RJ. Effect of Anti-Inflammatory Drugs on Overall Risk of Common Cancer: CaseControl Study in General Practice Research Database. BMJ 2000; 320 (7250): 1642-1646. 
611-616

5. Kelloff GJ. Perspectives on Cancer Chemoprevention Research and Drug Development. Adv Cancer Res 2000; 78: 199-334.

6. Selvakumar E, Hsieh TC. Regulation of cell cycle transition and induction of apoptosis in HL-60 leukemia cells by lipoic acid: role in cancer prevention and Therapy. J Hematol Oncol 2008; 1: 4.

7. Kono Y, Inomata M, Hagiwara $S$ et al. Antiproliferative effects of a new $\alpha$-lipoic acid derivative, DHL-HisZnNa in HT29 human colon cancer cells in vitro. Expert Opin Ther Targets 2012; 16 (1): 103-109.

8. Bernini R, Crisante F, Merendino N, Molinari R, Soldatelli MC, Velotti F. Synthesis of a novel ester of hydroxytyrosol and $\alpha$-lipoic acid exhibiting an antiproliferative effect on human colon cancer HT-29 cells. Eur J Med Chem 2011; 46 (1): 439-446.

9. Puvvada SD, Funkhouser WK, Greene K et al. NF-кB and Bcl-3 Activation Are Prognostic in Metastatic Colorectal Cancer. Oncology 2010; 78 (3-4): 181-188.

10. Labianca R, Nordlinger B, Beretta GD, Brouquet A, Cervantes A. Primary colon cancer: ESMO Clinical Practice Guidelines for diagnosis, adjuvant treatment and follow-up. Ann Oncol 2010; 21 (5): 70-77.

11. Haie-Meder C, Morice P, Castiglione M. Cervical cancer: ESMO Clinical Practice Guidelines for diagnosis, treatment and follow-up. Ann Oncol 2010; 21 (5): 37-40.

12. Kocic G, Pavlovic R, Najman S et al. Circulating Ribonucleic Acids and Metabolic Stress Parameters May Reflect Progression of Autoimmune or Inflammatory Conditions in Juvenile Type 1 Diabetes. ScientificWorldJournal 2011; 11: 1496-1508.

13. Simbula G, Columbano A, Ledda-Columbano GM, Sanna L, Deidda M, Diana A, Pibiri M. Increased ROS generation and p53 activation in alpha-lipoic acid-induced apoptosis of hepatoma cells. Apoptosis 2007; 12 (1): 113-123.

14. Feuerecker B, Pirsig S, Seidl C, Aichler M, Feuchtinger A, Bruchelt G, Senekowitsch-Schmidtke R. Lipoic acid inhibits cell proliferation of tumor cells in vitro and in vivo. Cancer Biol Ther 2012; 13 (14): 1425-1435.

15. Parker SL, Tong, T, Bolden S, Wingo PA. Cancer Statistics, 1997. CA Cancer J Clin 1997; 47 (1): 5-27.

16. Carreras CW, Santi DV. The catalytic mechanism and structure of thymidylate synthase. Annu Rev Biochem 1995; 64: 721-762.

17. Jetté L, Bissoon-Haqqani S, Le François B, Maroun JA, Birnboim HC. Resistance of Colorectal Cancer Cells to 5-FUdR and 5-FU Caused by Mycoplasma Infection. Anticancer Res 2008; 28 (4B): 2175-2180.

18. Copur S, Aiba K, Drake JC, Allegra CJ, Chu E. Thymidylate synthase gene amplification in human colon cancer cell lines resistant to 5-fluorouracil. Biochem Pharmacol 1995; 49 (10): 1419-1426.
19. Gray JH, Owen RP, Giacomini KM. The concentrativenucleoside transporter family, SLC28. Pflugers Arch 2004; 447 (5): 728-734.

20. Bunz F, Hwang PM, Torrance $\mathbf{C}$ et al. Disruption of p53 in human cancer cells alters the responses to therapeutic agents. J Clin Invest 1999; 104 (3): 263-269.

21. Loncar MB, Al-azzeh ED, Sommer PS et al. Tumour necrosis factor alpha and nuclear factor kappa B inhibit transcription of human TFF3 encoding a gastrointestinal healing peptide. Gut 2003; 52 (9): 1297-1303.

22. Hassanzadeh P. Colorectal cancer and NF- $\kappa B$ signaling pathway Gastroenterology and Hepatology From Bed to Bench 2011; 4 (3): 127-132.

23. Sakamoto K, Maeda S, Hikiba $\mathbf{Y}$ et al. Constitutive NF- $\kappa B$ Activation in Colorectal Carcinoma Plays a Key Role in Angiogenesis, Promoting Tumor. Clin Cancer Res 2009; 15 (7): 2248-2258.

24. Sakamoto K, Maeda S. Targeting NF-kappaB for colorectal cancer. Expert Opin Ther Targets 2010; 14 (6): 593-601.

25. Scartozzi M, Bearzi I, Pierantoni C et al. Nuclear factor- $\kappa B$ expression predicts response and survival in irinotecan-refractory metastatic colorectal cancer treated with cetuximab-irinotecan Therapy. J Clin Oncol 2007; 25 (25): 3930-3935.

26. Dolcet X, Llobet D, Pallares J, Matias-Guiu X. NF- $\kappa$ B in development and progression of human cancer. Virchows Arch 2005; 446 (5): 475-482.

27. Yu HG, Zhong X, Yang YN et al. Increased expression of nuclear factor-kappaB/RelA is correlated with tumour angiogenesis in human colorectal cancer. Int J Colorectal Dis 2004; 19 (1): 18-22.

28. Uetsuka H, Haisa M, Kimura $M$ et al. Inhibition of inducible NFkappaB activity reduces chemoresistance to 5-fluorouracil in human stomach cancer cell line. Exp Cell Res 2003; 289 (1): 27-35.

29. Kaltschmidt B, Kaltschmidt C, Hehner SP, Dröge W, Schmitz ML. Repression of NF-kappaB impairs HeLa cell proliferation by functional interference with cell cycle checkpoint regulators. Oncogene 1999; 18 (21): 3213-3225.

30. Fang LJ, Shao XT, Wang S, Lu GH, Xu T, Zhou JY. Sesquiterpene lactone parthenolide markedly enhances sensitivity of human A549 cells to low-dose oxaliplatin via inhibition of NF- $\kappa$ B activation and induction of apoptosis. Planta Med 2010; 76 (3): 258-264.

31. Li X, Wu G, Wu M, Chen W, Liu X. In vitro study of inhibitory millimeter wave treatment effects on the TNF- $\alpha$-induced NF- $\kappa \mathrm{B}$ signal transduction pathway. Int J Mol Med 2011; 27 (1): 71-78.

Received March 21, 2013. Accepted February 28, 2014. 